\title{
Jagdish Chandra Bose and Plant Neurobiology: Part I
}

\author{
Prakash N Tandon*
}

(Received 23 January 2019)

\begin{abstract}
Sir Jagdish Chandra Bose, a renowned physicist of Kolkata (Calcutta), in the early years of the twentieth century, progressively turned his attention to plant physiology. Utilizing some self-devised equipment he described the existence of nervous system in all varieties of plants. Recent years have seen a renewed interest in this field. Acknowledging Sir Bose's pioneering work, a new discipline of physiology_Plant Neurobiology has been revived. The paper provides a historical account of this work.
\end{abstract}

Key words: Action potentials, Electromagnetic waves, Plant physiology, Plant nervous system, Plant nerves, Sensory.

\begin{abstract}
"Thus the whole of the vegetable world, including the rigid trees perceive the changes in their environment and respond to them by unmistakable signals" (J C Bose 1918).

"I shall demonstrate my discovery of the nervous system in plants, and show how shocks from without pass within, and how this nervous impulse (is) modified during transit” (J C Bose 1918).
\end{abstract}

\section{Brief Biography}

Jagdish Chandra Bose was born on November 30, 1858 at Mymensingh (now in Bangladesh). His father Shri Bhagwan Chandra Bose was one of the earliest products of English education, who was appointed as a Magistrate by the recently established British rule in the country. Notwithstanding his 'exalted' position his father decided to send his son to a village pāthśāla , so as to imbibe the traditional culture of his people and life in the village. It was only when he was eleven years old that he was sent to Calcutta (Kolkata) to study at St. Xavier School for education in English. During this period he was exposed to workshops in carpentry, metal turning and even a foundry in a school founded by his father for orphan children. This experience helped him later in life when he started making his own research instruments (see later). After completing his school, he joined the St. Xavier College. It was here that under the influence of his teacher Father Eugene Lafont he got interested in Physics. However, in 1880 he was sent to England to study medicine. Owing to a chronic febrile illness (?Malaria, ?Kala-azar) he was advised to give up medical studies. He then joined Christ's College

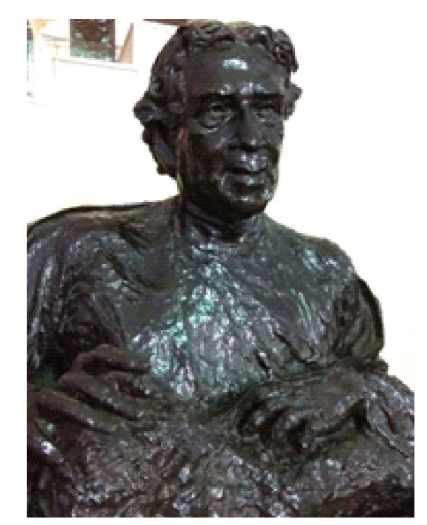

Fig. 1. Bust of J C Bose at the Bose Museum in Kolkata.

\footnotetext{
* National Research Professor, All India Institute of Medical Sciences, New Delhi-110029 and National Brain Research Centre, NH-8, Manesar, Gurgaon-12205; Corresponding address: 1 Jagriti Enclave, Vikas Marg Extension, Delhi-110092, Email: tandon@nbrc.ac.in.
} 
at Cambridge to study Physics, Chemistry and Botany for a natural science tripos. Here under the influence of Lord Rayleigh he decided to specialize in Physics. He took a BA degree in Science in 1883. This association with Lord Rayleigh was a constant source of help later in life when Bose struggled to get his research accepted in England. He also obtained a BSc degree from London in the same year.

Bose returned to India, as the first Indian Professor in Physics in the Presidency College in Calcutta in 1885. Here he established one of the first research laboratories in Physics, in a college, which went on to get internationally renowned. This was at a time when research by Indians in natural sciences was almost non-existent. On retiring from here in 1915, he established the Bose Institute which he guided till his last days.

For no obvious reasons, for nearly a decade after his return to India, scientific research does not seem to feature, at least as publications, among Bose's preoccupations. However, during this period, he had been actively pursuing his hobbies, like photography, recording voices on phonograph, visiting famous places of pilgrimage and cultural importance like Badrinath, Kedarnath, Konark and temples of south India and sites of ancient universities like Taxila, Nalanda, Sarnath, Bodh Gaya. With illustrative photographs, he wrote about these places in Bengali, published as articles and at least two books titled Abyakta and Juktakara. Interestingly, according to D M Bose, his nephew and successor as Director of Bose Institute, "on the completion of thirty fifth year of age on November 30, 1884, Bose resolved to devote himself to the pursuit of new knowledge". From here on there was unparalleled research output throughout his life. Though there is no record available of his scientific publications till 1895 , but obviously he must have been devoting himself to establishing a research laboratory because already in that year he published four papers including one in the Proceedings of the
Royal Society, London and yet another in the same journal in 1896 (Bose, 1895, 1896).

\section{Researches on Electromagnetic WaVes}

Initially Bose directed his research to study of electro-magnetic waves, an area of current interest globally. His first communication on the subject, "On the polarization of electric rays by double reflecting crystals" was to the Asiatic Society of Bengal in 1896 (Bose, 1896). Between 1894 to 1900 , he studied the optical properties of radiowaves and effect of these waves on inorganic matter. He carried out experiments on refraction, diffraction and polarization utilizing instruments developed by him in his small makeshift lab. Utilizing these instruments, he developed a microwave generator which produced wave length of the order of few millimeters, much smaller than had been produced before - and also designed 'coherers' (radio-wave detectors). He was the first person to use a semiconducting crystal to detect radio-waves. The 'Electric Eye' or 'Detector for Electrical Disturbances', a galena crystal semiconductor diode detector, sensitive to microwave/ millimeter and optical waves was the only one of Bose's numerous ingenious inventions that was ever patented (Shepherd, 2005).

In a public lecture in 1895 in the Town Hall in Calcutta, Bose demonstrated the ability of his electric waves to travel from the lecture room through an intervening room and passage to a third room 75 feet distant from the radiation sources, thus passing through three solid walls on the way, as well as through the body of Lieutenant Governor who presided over the meeting. The message received at the other end could release a relay enabling either a bell to ring, the discharge a pistol or explode a miniature mine. He set up a miniature antennae 20 feet high and planned to transmit signals from the laboratory to his house about a mile away (DM Bose). This was achieved before Marconi demonstrated wireless communication at longer wavelengths for which he was 
awarded the Nobel Prize in 1909. In 1998, IEEE accepted J C Bose as the inventor of the mercury drop coherer used by Marconi. A book by O E Dunlop Jr. "Marconi-the Man and His Wireless" (McGraw Hill, New York 1937, Reprinted 1971, Arno Press), which Marconi himself edited, devoted full one and a half page in tribute to Sir Jagdish Chandra Bose for providing crucial support to Marconi at the critical juncture when Marconi needed it most.

The historical electronics museum in Baltimore (USA) honoured the life and work of Bose in the year of his $150^{\text {th }}$ birth anniversary by inducting him into Pioneer's Hall of the museum as a permanent exhibit (Chaudhuri and Chattopadhyay, 2009).

In 1897, Bose gave a demonstration of his equipment at the Royal Institution in London. This led to a very lucrative offer in 1901 from a manufacturer of wireless apparatus which he refused being intellectually against patenting and commercialization of his research. In response to this potentially very lucrative offer, Bose felt, "I cannot find heart to give any part of my life for money making purposes". In a letter written by Bose to Rabindranath Tagore on this issue, "I wish you could see that terrible attachment for gain in this country ...that lust for money ... Once caught in that trap there would have been no way out for me" (Banerjee, 2010). Between 1885 and 1900, he published 10 papers in the Proceedings of the Royal Society, London. All of these were related to his work concerning electro-magnetic waves and were communicated to the Royal Society by his former teacher Lord Rayleigh. There were some other papers which were published in Electrician, a well-known weekly journal devoted to 'Electric Engineering, Industry and Science'. As a matter of fact this journal published a laudatory Editorial in 1900 on Bose's recently devised instruments related to his work on radiowaves.
The preceding account on Bose's biographical aspects and researches in the broad field of Physics are included here since these have a direct bearing on turning his attention to an 'apparently' new field of Plant Physiology. In reality it was a direct extension of his overarching belief in the Unity of Life, which was the subject of his talk to the Guild House in London on $30^{\text {th }}$ June 1929. Along with his friend Rabindranath Tagore, Bose had his belief firmly rooted to the preaching of the ancient Hindu upanișads and the vedas, which concerned nature not merely as a physical phenomenon but, a living spirit which could help man to realize the essential Truth of Life (Banerjee, 2010).

\section{Transition from Physical to Physiological}

It was the potential of his new instrument $-\mathrm{a}$ "detector coherer" - using which he first demonstrated the coherence action of different matters (Bose, 1899), that made him to compare the reaction between inorganic and organic - (nonliving and living) that turned his attention to plants.

One of the earliest evidence of Bose's new interest in Plant Physiology was reflected in his address to the International Congress of Physics, held in Paris in 1900. The title of his talk, was "On the Similarity of responses in Inorganic and Living Matter", which was later published in the Electrician. At the conclusion of his lecturedemonstration to the Royal Institution in London next year he remarked, "Do not these records show us that the responsive process seen in life, have been fore-shadowed in non-life? That the Physiological is related to Physico-chemical? That there is no abrupt break, but a uniform march of law?" He ended his lecture with the following peroration:

I have shown you this evening autographic records of the history of stress and strain in the living and non-living. How similar are the writings. So similar indeed that you cannot tell one apart from the other. We have watched the response sinking under fatigue, 
becoming exalted under stimulants, and being killed by poisons, in the non-living as in the living. Among such phenomena, how can we draw a line of demarcation, and say, here the physical ends and there the physiological begins. Such absolute barriers do not exist (D M Bose).

Thus, already in 1902, he published a monograph, "Response in the Living and Non-Living" [Longmans, Green \& Company, London] ${ }^{1}$.

\section{Plant Physiology}

From 1900 onwards, Bose devoted himself to the application of his knowledge of Physics to explore the Physiology of the Plants. During this period of over three decades he studied those intricacies of Plant Physiology which nobody else had studied earlier. Starting with study of Mimosa pudica and Desmodium gyrans he studied a large number of plants - small herbs and big trees, both those growing on soil and in water. In his own words,

\begin{abstract}
Before us are spread multitudinous plants, silent and seemingly impassive. They too like us, are actors in the cosmic drama of life, like us the plaything of destiny. In their checkered life, light and darkness, the warmth of summer and frost of winter, drought, and rain, the gentle breeze and whirling tornadoes, life and death alternate. Various shocks impinge on them, but no cry is raised in answer. I shall nevertheless try to decipher some chapters of their life history (Prof. Bose in his discourse at the Bose Institute on the $7^{\text {th }}$ February, 1919).
\end{abstract}

He thus laid the foundation of Biophysics in the country (Chaudhuri \& Chattopadhyay, 2009). In absence of previous such studies he not only formulated his own theories and hypothesis but also designed and fabricated his own instruments. The ingenuity of these research tools is in itself an unparalleled feat. It is not surprising then that the authenticity of the results derived from their use aroused disbelief for several years among his peers. It took several years of often 'cantankerous' criticism before their authenticity was not only acknowledged but admired. The admirable strength of his self-confidence and belief in himself is itself noteworthy. A brief account of these ingenious instruments is therefore included here:

Growth Recorders: (a)The Optical and Recording Crescograph which magnify the response ten thousand times; (b)The Magnetic Crescograph with its practically unlimited magnification. The high magnification could measure tiny increment of growth in intervals of a second, under normal conditions or with chemical or electrical stimulation. In his own words, Bose in his paper, "Automatism in Plants and Animals" declared, "My recently invented Crescograph...will magnify growth a million fold, ultramicroscopic movements, smaller than a single wave length of light" (Bose, 1908); (c)The Photosynthetic Bubble and Recorder; (d)The Electric Probe - one of the earliest intracellular microelectrode, whose tip was in circuit with a sensitive galvanometer and could be driven into tissue in $0.1 \mathrm{~mm}$ increments, and microelectrodes, which were connected to various parts of a plant with saline kaolin paste; (e) The Resonant Recorder which had "frictionless" jeweled bearings, fine lightweight horizontal lever connected to various parts of the plant and a vertical lever for writing the response on a smoked glass plate which moved at a uniform rate.

With his numerous experimental set-ups, Bose was able to simultaneously measure:

- Plant electric potentials and very small electrical oscillations

\footnotetext{
1 It is interesting to note that Swami Vivekananda who was in Paris at this time wrote, "Here in Paris have assembled the great of every land, each to proclaim the glory of his country. Savants will be acclaimed here; and its reverberation will glorify their countries. Among these peerless men gathered from all parts of the world where is thy representative "thou country of my birth? Out of this vast assembly, a young man stood for thee, one of thy heroic son; and blessed be his devoted and peerless helpmate who stands by him always [D M Bose]"
} 
- Apply mechanical (touch, pricking, cutting) or electrical stimuli or chemical inhibitors (anesthetists) or poisons to the plants

- Varying light conditions, temperature, hydrostatic and osmotic pressure to which the plant was exposed

- Measure plants movements

- Measure tiny growth increments over very short time intervals for reasonable length of time

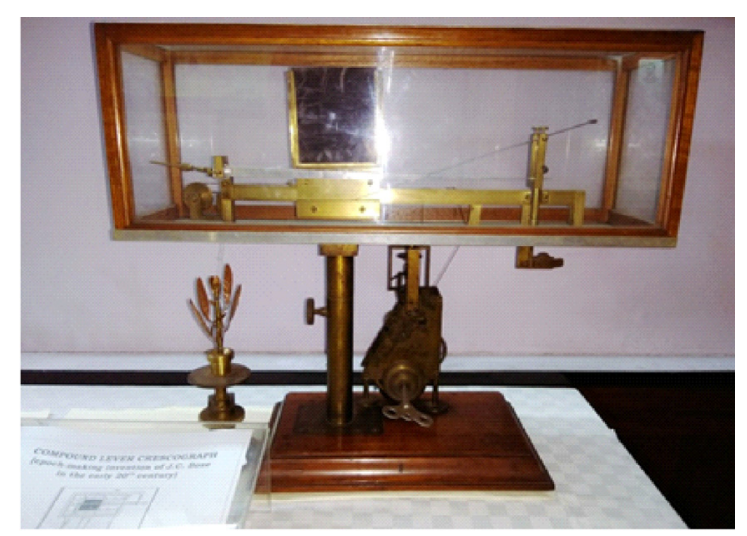

Fig. 2. Compound Lever Crescograph- An apparatus invented by JC Bose in early $20^{\text {th }}$ century, on display at the Bose Museum in Kolkata.

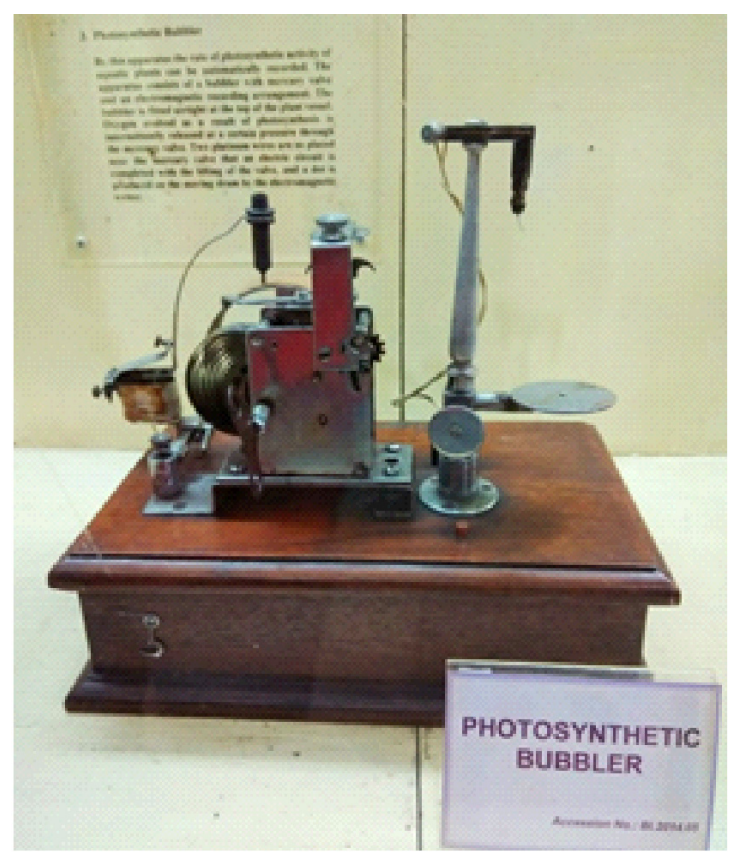

Fig. 3. Photosynthetic Bubble.
According to Galston and Slayman (1979),

..... Bose certainly does deserve great credit. With vast ingenuity, he designed sensitive and elegant instruments to measure small changes in electric potential and small changes in shape (bending, swelling, etc) of plant materials. With these instruments he was able to demonstrate withdrawal movements of plant tissues from sites of injury, complementing for 'ordinary' plants the much more conscious movements displayed by various insectivorous and photoperiodically sensitive plants (e.g. Venus's flytrap, Sundew and Mimosa). He also described event in aquatic higher plant that resembled action potential (Bose, 1924).

\section{Plant Nervous System: Seeds of Plant Neurobiology}

Charles Darwin (along with his son Francis) later in his life turned towards plants in addition to his other better known researches. Darwin (1875) demonstrated the existence of electrical signals in insectivorous plants. In one of the books, The Power of Movements of Plants published in 1880, Darwin proposed that,

It is hardly an exaggeration to say that the tip of the radicle thus endowed (with sensitivity) and having the power of directing the movements of the adjoining parts, acts as the brain of one of the lower animals; the brain being seated within the anterior end of the body, receiving impressions from the sense-organs and directing the server of movements.

The so-called 'Root-Brain' hypothesis of Darwin was not accepted by leading botanists of the day (Baluska et al., 2009). The same was true for the observation by Burden Sanderson made two years earlier. It was thus to the credit of the meticulous experiments carried out by Bose from 1900 onwards to provide unequivocal evidence of the existence of a functional system like the nervous system in all types of plants. Having already demonstrated electric response in ordinary plants under mechanical stimulus and electrical pulsations accompanying automatic plant movements in Desmodium gyrans in 1902, Bose went on to explore in details all aspects of this 
system in a large variety of plants using the ingenious instruments mentioned earlier for the next three decades. Thus according to Shepherd (2005),

... he was the first to recognize the ubiquitous importance of electrical signaling between plants cells in coordinating responses to the environment. He provided direct evidence that the long-distance, rapid electrical signaling stimulated leaf movements in Mimosa and Desmodium and also showed that plants produce continuous, systemic electrical pulses.

He concluded that not only Mimosa and Desmodium but all plants co-ordinate their movement and responses to the environment through electrical signaling.

\subsection{Plant Nerve and Action Potentials (A-P)}

\subsubsection{Action Potentials (AP)}

Action potentials were discovered in insectivorous plants in early 1870s (BurdonSanderson, 1873; Darwin, 1875), at that time the animal brain was still unexplored and the cellular, basis of neuronal circuits was not yet accepted (Baluska et al., 2005). However, Bose (1906) had already established the nervous impulse and its transmission in the plants using his ingeniously devised instruments, as mentioned earlier. He not only established the existence of AP but also measured the speed of the nervous impulse. This was true for all plants and not just the insectivorous ones. Notwithstanding its public demonstration by him at various places in UK and Europe, it did not receive general acceptance. On the contrary this was labeled as 'pseudoscience', 'illusionary science' and 'doomed for oblivion' (Baluska et $a l ., 2005)$. Some aspects of the earliest studies on plant 'nervous system' documented by Bose himself in his diary and letters need to be briefly summarized:

In a letter to the Editor of Nature: "In my letter which you kindly published in your issue of $10^{\text {th }}$ January (Bose, 1901), on Transmission of Stimuli in Plants, I expressed a hope of being able to publish detailed account of my recent experiments at an early date. As this is likely to be delayed I am sending a summary of results for publication in your valued journal: [A detailed account of 11 points was sent]

Point 3: "By means of the Electric Probe the conducting or nervous tissue has been localized in the phloem of fibro-vascular bundle... The definite innervations of the four quadrants of the pulvinus are demonstrated by the characteristic effects produced by peripheral and central stimulation".

Point 9: "Two different conducting elements have been discovered and localized in the nerve-strand of Mimosa of which one conducts the afferent or sensory and the other the efferent or motor impulse".

Point 11: "The extra ordinary similarity between the physiological reactions in the plant and in the animal which is thus demonstrated establishes the generalization that the nervous mechanisms is essentially the same in the two types of living organisms".

It appears to be the first time when Bose referred to the existence of nervous tissue in the plants responsible for their sensory perception and motor response mediated by the electrical potentials.

In another letter to Nature published in October 2, 1902, Bose clarified that the claim of Dr. Waller about the priority of his observations on plant electric response was untenable.

Dr. Waller not only heard me describe these results, but took part in the subsequent discussion of my paper. It is indeed very strange that he should on that occasion have said absolutely nothing about his being engaged in this particular investigation. An eminent physiologist declared during the discussion that the electric response of ordinary plants under mechanical stimulus was an impossibility. Dr. Waller, who immediately followed him, it is again remarkable to note, had not one word to say for the possibility of such a phenomenon. These facts are as significant as the fact that Dr. Waller communicated his paper five months after he discussed mine at the Royal Society.

The above will dispose of the question of priority. My Linnean Society paper and Dr. Waller's paper read before the Physiological 
Society are now before the public. "From these, anyone interested in the subject will be able to determine the scope of the two investigations, the novelty of the appliances and methods employed, and the accuracy of the results obtained". This controversy regarding priority of establishing electrical activity in plants between Bose and Waller has been discussed in details by Subrata Dasgupta in 1998. Following a critical evaluation of all available information Dasgupta arrived at two conclusions worth mentioning,

\footnotetext{
Regrettably, neither Bose nor Waller emerged untainted from this episode. At the very least, they both committed sins of omission. And the evidence seems to indicate that Waller's sin was the greater one. And, "As to the question: who of Bose and Waller could claim rightful priority for the discovery of 'vegetable electricity'? Though the evidence is not unequivocal, it would appear that Bose's claim was the stronger one".
}

However, today not only its existence but its significance for control of many physiological functions of the plant, already elaborated by Bose e.g. respiration, photosynthesis and motor activity have been confirmed by numerous investigators giving rise to the burgeoning discipline designated as Plant Neurobiology (Barlow, 2008). As mentioned by Shepherd (2005), 'against the tide of times, Bose proposed that plants have a welldeveloped nervous system. He argued that longdistance electrical signaling is of major importance in plant responses to the environment'. Zawadzki et al. (1991) re-affirmed its similarity to AP in animals, as repeatedly emphasized by Bose (1924, 1926). Thus Zawadzki (1991) pointed out that, "The AP is a 'genuine' electrical signal. It can be evoked electrically, it has 'all-or-nothing' character (below a threshold stimulus there is no response, while above this threshold, there is maximum response) and it travels with constant velocity and magnitude". The AP is a self-perpetuating signal, based on the activity of voltage-gated channels which respond to, (and causes) changes in membrane potential (Davies 1993). This has been further elaborated by Brenner et al. (2006) "At the molecular level, plants have many, if not all the components found in animal neuronal system. There are action potentials, voltage gated channels, a vesicular trafficking apparatus, sensitive calcium signals including synaptotagmines and other components of the neuronal cell infrastructure" (similar to animal nervous system). This has been further elaborated by Muday and Brown Harding (2018) under the tittle "Nervous system like signaling in plant defense" and Toyota et al. (2018).

\subsection{Microelectrode Recording of Electrical Activity}

As mentioned earlier the first extracellular recording of a plant AP is reported to have been initiated by Charles Darwin in 1875 and performed on leaves of Venus fly-trap Dionea muscipula. However, this was not generally accepted by the leading botanists of the time. Julius Sachs even castigated the Darwins (Charles and his son Francis) for their careless experiments (Brenner et al., 2006). However, it was Bose, who devised the 'Electric Probe' one of the earliest intracellular microelectrode (referred to earlier) which could be driven into various parts of a plant connected to a sensitive recorder, which unequivocally demonstrated the AP during his lecture demonstrations in International Conference in Physics at Paris in 1900; and at the British Association meeting at Bradford also in 1900 and later published in the journal Electrician; before the Royal Institution of London on May 10, 1901; and in June 1901, before the Royal Society (D M Bose). These experiments were detailed in a series of papers (Bose 1902, 1908, 1914) and a number of Monographs Responses in the Living and NonLiving (1902); Plant responses as a means of Physiological Investigations (1906); Comparative Electro-physiology (1907); Researches on Irritability of Plants (1913); Nervous Mechanisms of Plants (1926); Plant Autographs and their Revelations (1927); Motor Mechanisms of Plants 
(1928) [all published by Longmans]. These microelectrodes intracellular recordings of plant cells, using his personally fabricated ingenious equipment's, to the best of my knowledge, preceded such studies on animal nervous system.

According to Brenner et al. (2006) Bose, "was the first to recognize the ubiquitous importance of electrical signaling between plant cells in coordinating responses to the environment". He, (Bose) "provided direct evidence that longdistance, rapid electrical signaling stimulated leaf movements in Mimosa and Desmodium and also showed that plants produce continuous systemic electric pulses. They further commented that, "Bose's overall conclusion that plants have an electro-mechanical pulse, a nervous system, a form of intelligence, and are capable of remembering and learning, was not well-received in its time". In his Inaugural address during the dedication of the Bose Institute on the $30^{\text {th }}$ November, 1917(Bose, 1918), Bose went further than physiology of the nervous system of plants, "A question long perplexing physiologists and psychologists alike is that concerned with memory. But now through certain experiments I have carried out it is possible to trace "memory impressions". A hundred years later, concepts of plant intelligence, learning, long-distance electrical signaling in plants have entered the mainstream literature" (Brenner et al., 2006). Confirmation of these higher order nervous functions in recent years has led to the development of a new scientific discipline called Plant Neurobiology - which will be discussed in Part II of this presentation providing an overview of the current status of the subject.

However, before concluding this essay let me quote some poetic statements by Bose on the subject of this essay.

At one place he wrote, “... These trees have a life like ours... They eat and grow... Face poverty, sorrows and sufferings. This poverty may... induce them to steal and rob... They help each other, develop friendships, and sacrifice their life for their children..." (Nandy,1995).

In his talk while paying homage to his friend Rabindranath Tagore on the occasion of the $70^{\text {th }}$ Birthday of the Poet in 1931, Bose mentioned,

\begin{abstract}
His (Tagore's) friendship has been unfailing through years of my ceaseless efforts during which I gained step by step a wider and more sympathetic view of the continuity of life and its diverse manifestations. It was in following this quest that I succeeded in making the dumb plant the most eloquent chronicler of its inner life and experiences by making it write down its own history. The self-made records, thus made, prove that there is no life-reaction in even the highest animal which has not been foreshadowed in the life of the plant (Banerji, 2010).
\end{abstract}

Bose (1907) measured action spikes (Action Potentials) in Mimosa plants where they preceeded the visible folding movements of the leaflets. Studies with isolated vascular bundles (e.g. from the fern Adiantum) Bose (1907) found increasing amplitude of heat induced spikes by repeated stimulation (titanisation) and incubation in $0.5 \%$ solution of sodium carbonate. Since the electrical behavior of these vascular strands was comparable to that of isolated nerves, he felt justified to refer to them as 'plant nerves' (Bose, 1907, 1925, 1926; Stahlberg, 2006). In his paper in Modern Review in 1908, Bose summarized his accumulated observations till date as follows: "One of the most characteristic signs of the presence of life is the power to give a reply, of one kind or another to a stimulus. The same thing is seen in Mimosa or sensitive plant, when the excited leaf suddenly falls down, or similarly, under the excitation of touch, the open Drosera leaf closes on the fly, its prey. Instead of this mechanical movement in response to stimulus, and a suitable instrument, the galvanometer, shows an electric twitch, each time the living tissue is excited". A paper "The Nervous Impulse in Plants' published in Italian Journal Scientia in January 1928, Bose stated, "I have been able to localize the nerve in plant by 
two independent methods, the first of which is the method of the Electric Probe"... And "The nerve distribution in the plant has also been distinctly made out by selective staining. The nerve tissue... consists of elongated tubular cells, the dividing membrane of which acts alike a synapse in the animal (Bose, 1928)".

On another occasion he elaborated this further, "It can only be in virtue of a system of nerves that the plant constitutes a single organized whole, each of whose part is affected by every influence that falls on another". According to Peter Barlow (2008) Bose was the first to use the term 'plant nerve'. Recently Volkov (2006) drew a parallel between plant phloem and animal axons and claimed that, "phloem is an electrical conductor of bioelectric-chemical impulses over long distances...structures of phloem and axon can be pictured as hollow tubes filled with electrolyte solutions".

\subsection{Automatism in Plant and Animal}

In a 'Review' under this title Bose (1908) demonstrated the 'automatic' or 'spontaneous' movements in plants, i.e. 'occurrence of effects seemingly without a cause'. He compared it to the rhythmic beating of the heart in animals. He emphasized, "...such rhythmic tissues are not found only in animals. They occur also in the plants...". And pointed out, "I was fortunate enough to be able to make a continuous record of these pulsatory movements during 12 hours". In addition, he studied the effect of temperature and poison on these pulsations. Challenging the prevailing view about the ascent of the sap, a stream of fluid charged with food materials from below upwards, he attributed it to such pulsatory movements.

\subsection{Response to Environment: Sensory - Motor Functions and Reflex Arc}

In one of his lectures Bose stated, "In June 1901, I exhibited before the Royal Society the electric response of all plants proving their sensibility. He went on to elaborate, "Does the tissue of an ordinary plant exhibit a shuddering twitch under shock? Such a movement has never been suspected. My newly invented Cellular Recorder actually records and measures the contraction of a microscopic cell even when all movement is physically restrained..." (Bose, 1900). In another lecture at the Bose Institute in 1918, explaining the 'Mystery of Praying Palm Tree', he described his experiments which provided a scientific explanation for this 'Mystery' by demonstrating that the 'mysterious' movement of the tree coinciding with the ringing of temple bells was in reality related to changes in environmental temperature. He observed, "Records obtained (also) with other trees brought out the extraordinary and unsuspected fact that all trees are moving - such movements being in response to changes in the environment". My investigations prove, "that not only has nervous system been developed, (in plants), but it had attained a high degree of complexity as marked by the reflex arc in which the sensory becomes transformed into a motor impulse" (Bose, 1918).

Bose extended his studies to record sensitivity of the plants to the environmental stimuli and concluded, 'That not a 'Mimosa' alone, but all plants are sensitive..." and, "Further experiments were shown demonstrating the effect of light, of warmth and other stimuli on the plant". "Thus the whole of vegetable world, including rigid trees perceive the changes in their environment and respond to them by unmistakable signals". In conclusion of this talk Bose stated, "I shall demonstrate my discovery of the nervous system in plants, and show how shocks from without pass within, and how this nervous impulse modified during transit" (Bose, 1918). He concluded that "plants coordinate their movements and responses to the environment through electrical signaling" (Shepherd, 2005). Poetically extending these comments he stated, "They thrill under light and 
become depressed in darkness: the warmth of summer and frost of winter, drought and rain, these and many other happenings leave a subtle (sic) impress on the life of the plant". It is not surprising that Rabindranath Tagore described Bose as, "a poet in the world of facts" (Banerjee, 2010).

In yet another talk, the same year, he discussed, 'Control of Nervous Impulse'. He pointed out that, "Before proceeding further, it will be necessary first to obtain a clear idea of the function of the nervous tissue, and its characteristics; secondly, the manner in which the nervous impulse is propagated, and lastly we have to discover some compulsive force by which the impulse may be intensified or inhibited during transit". He concluded, "The propagation of nervous impulse is a phenomenon of transmission of molecular disturbance" (Bose, 1918). It is worth noting that this statement antedated by many years the birth of molecular biology. In another talk in 1921, 'The Surge of Life', he reiterated his findings; "The results of various experiments brought the plants much nearer to us than we thought. We find that it is not merely a mass of vegetative growth, but that its every fibre is instinct with sensibility. We find it answering to outside stimuli". And further on, "We have seen how the whole plant is made one by the conducting threads, so that the tremor of excitation initiated at one place courses through the whole and how nervous impulse, as in man, can be accelerated or arrested under the several actions of drugs and poisons" (Bose, 1921).

Bose published his quarter of a century work in his monograph, The Nervous Mechanisms of Plant in 1926. On the basis of his extensive and precise studies he stated, "Plants also have receptors for stimuli, conductors (nerves) which electrically code and propagate the stimulus and efforts or terminal motor organs". Thus, “... physiological mechanisms of the plants is identified with that of the animal" (Bose, 1926).

\subsection{Sense Organ of Plants}

In a lecture delivered at the Bose Institute on the $25^{\text {th }}$ February 1921, Bose comparing the sense organs of the animals and plants, proposed that, "We shall find similar sense organs possessed by plants by means of which its various parts place themselves in favorable attitude so as to gather energies derived from outside - so essential for the maintenance of life activity itself. We shall find that it has organs which respond to touch, rudimentary eyes to perceive light, and special organs by which it perceives direction in space". It is obvious that these presumptions were made on the basis of observations of such responses movement towards light, response to touch, warmth and cold and electric shock and physical and chemical trauma referred to earlier. At another place Bose comparing plants to stationary zoophytes - polyps - states that "The plant like polyp sees light, feels contact, respond to heat and cold". Though Bose refers to his invention of 'Electric Probe' 'by means of which it is possible to explore the interior of a living plant and detect the state of excitation in its different layers'. It is obvious from the above statements that he hoped to or expected to find such organs. He, however claimed that, "He has been able to localize the special layer of cells which perceives the stimulus of gravity" (Bose, 1921). According to D M Bose, J C Bose's experiments on Plant Responses showed that,

\footnotetext{
Like animals, plants have also elementary sense organs. If a young wheat seedling is placed horizontally, then after sometime its growing tip bends downwards. These growing regions contain receptor organs sensitive to gravity. The growing stem tip-has also a light receptor organ; when illuminated from one side for short period with light, the stem will bend towards the light source. The growing tendril of a climbing plant will always wind around a support with which it comes into contact; it is sensitive to mechanical stimulation.
}

Thus JC Bose was the first to show that in all such cases of response of plant-stems to stimula- 
tion, whether due to gravity, light, mechanical contact, the curvature produced is always accompanied by an electrical field such that the concave side is negative and the convex positive (Bose, D M, 1966). Obviously, the existence of various sense organs in plants was based on circumstantial evidence. The present author has failed to find any description of either of their structure or location in any of Bose's published papers.

In an address delivered on the $6^{\text {th }}$ December 1923 before the Royal Society of Medicine, Great Britain, Bose refers to his two books, Physiology of the Ascent of Sap (already published) and Physiology of Photosynthesis (shortly to be published) he stated that, "I shall describe a new method and appliance I have devised, which enabled me to probe into the interior of the organisms". Though this does not directly deal with the nervous system of the plants, his observations in respect to the cellular activity responsible for the Ascent of Sap, there is an indirect reference to the nervous system. "Further experiments prove that a definite active tissue extends throughout the length of the tree, the cellular pulsations of which in regular sequence cause, by their pumping action, the propulsation of sap" (Bose, 1923).

In yet another talk on 'Life and its Mechanisms' delivered at the Bose Institute on the $30^{\text {th }}$ November 1924, under the section, "Do Plants Feel?" he stated, "my scientific results proved beyond a shadow of doubt that many plants possess not merely a rudimentary, but a highly elaborated nervous system". And furthermore, "In regard to the nervous system I have been able to localize the nerve strand in plants, the trace of fibres which innervate the motor organ. I have been able to paralyze these nerve strands by the action of various narcotics or render them extraordinarily irritable by action of certain specific drugs" (Bose, 1924).

\subsection{A note on Controversies aroused by Bose's work on Plant Nervous System}

In his address at the Tenth Anniversary of the Bose Institute on the $29^{\text {th }}$ November, 1927, Bose recounted the opposition to his work following his demonstration of the electric response of plants proving their sensibility in June 1901 before the Royal Society (Bose, 1927). He acknowledges that his observations were not only doubted but also considered 'experimental artifacts' and 'pseudoscience'. He struggled against all this opposition fully realizing that 'the revolutionary doctrine' may not find acceptance in his life-time.

In May 1901, Bose made a presentation at the Friday Evening Discourse at the Royal Institute, London. This was followed by a lecture at the Royal Society, London. This paper though never published, it served a notice of Bose's transmutation from a highly respected physicist to a controversial plant physiologist (Dasgupta, 1998). The following extracts from his diary noting dated 26 March 1902 reflect the extent of disbelief in Bose's observations among many distinguished biologists in England at the time.

\footnotetext{
Professor Vines, who was one of his teachers at Cambridge and great supporter of Bose through the period of the early controversy, informed Bose, that "Sanderson told him (Vines) that what Bose showed was an accidental current due to rusting of wire". When Professor Hartog, a prominent biologists of Cork, was asked to attend Bose's lecture demonstration he (Hartog) remarked, "Do you take me to be drunk that I should believe in such nonsense". However, Hartog still attended the lecture and, "When he saw photographic records projected by lantern he at once made up his mind that these were faked, for such absolute resemblance could never exist between the response of muscle and carrot. But when he saw these records actually traced before his eyes by my (Bose's) automatic recorder his astonishment knew no bound. So it was with every one of my audience. Each of them came to see the absurd claim exploded, but after seeing the experiment swang to the other extreme of enthusiastic appreciation" [Bose's Note Book: London 26 $6^{\text {th }}$ March 1902].
} 
His earliest paper on the subject was rejected by the journal of the Royal Society. He demonstrated his instruments and experimental observations at various centres in Europe. However, as late as 1920, there was a controversy in The Times (the prestigious British Newspaper) "as to the reliability of my super-magnifying instruments in the accurate record of the automatic pulsations of the plant and its responsive movement under an external shock". An enquiry was therefore undertaken by a committee of leading Fellows of the Royal Society, among whom were Sir William Bragg, the renowned physicist and Sir William Bayliss, the eminent physiologist. They reported that from various tests carried out, they were fully satisfied "that my Magnetic Crescograph correctly recorded the response of plants at a magnification of ten million time". Bose further reported that, "The following plant-physiologists holding positions of outstanding eminence - Herberlandt in Berlin, Molisch in Vienna, Pringsheim and Nemec in Prague, Chodat in Geneva, Mangin in Paris, Timiriazeffs in Russia and Vines in England warmly welcomed the scientific advance" (Bose, 1927).

\section{Discussion}

Bose a physicist, initiated his research studying optical properties of the short-length radio-waves generated, for the first time with instruments he designed himself. He also developed a 'Detector' for electric disturbance. With these instruments he demonstrated the ability of electric waves to function as wireless communication system. He went ahead to use his equipment to study the response of inorganic matter to mechanical and electrical stimulation. Finding this response similar to electrical response of a muscle he regarded this as an evidence for 'Life'. He, therefore, proceeded to study this response in plants. He demonstrated this, hitherto, undiscovered phenomenon at a number of prestigious institutions abroad, like British Association Meeting, Royal Institution and Royal
Society, London around 1901-1902 and later in several other European countries. In his own words, "these revolutionary observations aroused much critics and disbelief'. Undeterred by this setback he went ahead refining his studies with the help of a series of new instruments like optical and magnetic crescograph, the electric probe and microelectrodes etc.

Before discussing the results of more than three decades of his work (1900-1935) on plant electro physiology, it is important to briefly review the contemporary scenario in the field of animal electricity. Towards the end of $18^{\text {th }}$ Century Luigi Galvani from Italy, showed that animals had electricity. Nearly a century later BurdenSanderson (1873) and Charles Darwin (1875) demonstrated the existence of electrical signals in insectivorous plants. These observations were not taken seriously by the contemporary scientific society. However, Charles Darwin continued his researches on plants along with his son Francis for some more years. In their book, Charles and Francis Darwin (1880) The Power of Movements in Plants, proposed that, "It is hardly an exaggeration to say that the tip of the radicle thus endowed (with sensitivity) and having the power of directing the movements of the adjoining part, acts as the brain of the lower animals, the brain being seated within the anterior end of the body, receiving impressions from the sense-organs and directing the server of the movements" (Quoted by Baluska et al., 2009). This came to be known as the 'root-brain' hypothesis. As a matter of fact in his address before the British Association in Dublin in 1908, Charles Darwin made a somewhat unusual hypothetical assertion, "it is consistent with the doctrine of continuity that in all living things there is something psychic, and if we accept this point of view we must believe that in plants there exists a faint copy of what we know as consciousness?" Not having access to these original publications it is hard for the author to know as to the experimental observations that led to these assertions. 
Around the same time one of the most renowned neuroscientists, Santiago Ramon yCajal (1852-1934) is believed to claim that, "Neurons generated electrical signals and were responsible for the many functions of the brain, receiving sensory inputs, processing this information, storing memories, learning and controlling our muscles (Ramon y- Cajal, 2017). Cajal propounded the Neuron Hypothesis in 1894 while Sir Charles Sherrington advanced the Synaptic Hypothesis in 1898 (which was verified by Cajal)". With his uncanny insight Cajal proposed the principle of dynamic polarization i.e., the unidirectionality of the neuronal signals. Hitzig in Zurich discovered the electrical excitability of certain parts of the cerebral cortex in 1870 .

It is worth recording that Edgar Adrian in London described the method of recording from single sensory and motor axon between 19281932. This new technology enabled neurobiologists to relate neuronal signaling directly to a specific event such as presentation of a sensory stimulus (Adrian, 1957). By 1930s, electrophysiological methods were sufficiently refined to enable recordings to be made from individual neurons in animals. John Eccles has been credited for using intracellular recordings from neurons to reveal the ionic mechanism through which motor neurons generate the inhibitory and excitatory actions that permit them to serve as the final common pathway for neuronal integration (Eccles, 1953, 1964).

From the foregoing account it appears that Bose's electrophysiological observations which started with demonstration of electrical responses in plant in 1900 and proceeded to establish the receptors, the action potentials, their unipolar spread, along with the 'plant nerve' through the synapse resulting in the motor (effector) activity thus completing the reflex arc, using highly sensitive self-devised instruments, were original contributions. While Burden-Sanderson (1873) and Darwin (1875) demonstrated the existence of electrical signals only in insectivorous plants, Bose unequivocally demonstrated these in all plants. In his own words in his book, The Nervous Mechanisms of Plant, Bose (1926) summarized these observations thus, "Plants also have receptors for stimuli, conductors (nerves) which electrically code and propagate the stimulus and effectors or terminal motor organs". In essence, "... the physiological mechanism of plants is identical with that of the animal". Furthermore, Bose's researches were not just restricted to demonstration of electrical activity in plans but existence of a functional nervous system in all plants. As mentioned by Shepherd (2005), "against the tide of times, Bose proposed that plants have a well-developed nervous system. Thus in recent years a number of biologists and plant physiologists acknowledged that Bose was the first in establishing the ubiquitous importance of electrical signaling between plants cells, in coordinating responses to the environment (Galston \& Slayman,1979; Shepherd, 2005; Brenner et al., 2006; Barlow, 2008).

It is equally remarkable that while the first extracellular recording of the action potential in plants has been attributed to Darwin (1880), it is to the credit of Bose to devise the intracellular recording set up as early as 1906 . The set of instruments devised by Bose (described earlier) was unique in itself and certainly prior to the equipment used by pioneers of animal microelectrode studies. It is surprising that intracellular recording from nervous system in animals started at least twenty years after those reported in the plants by Bose. One wonders why pioneers of intracellular studies in animal nervous system, like Adrian and Eccles, did not refer to the earlier studies in plants. ${ }^{2}$ I hasten to add that I have personally not seen Bose's electrographic

\footnotetext{
2 At least the present author has not come across such reference, even though one is familiar with use of intracellular recordings of animal nervous system by pioneers like Vernon Mount Castle (1957), David Hubel and Torsten Wiesel (1959).
} 
intracellular recordings reported in the fairly large numbers of papers published by Bose to which I had access. However, this is not to doubt his claims in this regard. Considering the fact that Bose gave lecture-demonstration at some of the most prestigious organizations in London as the Royal Institution, the Royal Society, published several monographs by Bose (1926, 1927 1928) Longmans $(1913,1927,1928)$ and papers and correspondence in Nature, Proceedings Royal Society, London, and was a subject of some controversies about his work in The Times (1920) following which a committee of Royal Society confirmed Bose's observations, it is unlikely that prominent British neuroscientists like Adrian, Sherington and Eccles were not aware of Bose's contributions in plant electrophysiology. Yet neither the benefit of his technology for recording the plant electrophysiology, independently tested by the Royal Society Committee, was either utilized or commented upon in their publications on microelectrode extracellular or intracellular recordings carried out several years later. It is, however, to the credit of recent plant neuroscientists like Shepherd (2005), Barlow (2008), Brenner (2006), Baluska (2003, 2005), Trewavas (1999, 2005), Stahlberg (2006) to acknowledge and confirm Bose's pioneering contributions, while advancing these further under the rubrick of "Plant Neurobiology", which is the subject of Part II of this paper.

\section{ACKNOWLedgment}

The author acknowledges with thanks Dr. Nihar Ranjan Jana and Dr. Pankaj Seth, NBRC for help in procuring some of the important reference material. Author would like to thank the Director, Bose Institute, Kolkata for kindly providing consent for using the pictures of JC Bose's equipment from the $\mathrm{J}$ C Bose Museum.

\section{BiBLIOGRAPHY}

Adrian, E D. The Analysis of the Nervous System: Sherrington Memorial Lecture, Proc R Soc, 1957.
Baluska, F; Samaj, J and Menzel, D. Polar Transport of Auxin: Carrier-mediated Flux across the Plasma Membrane or Neurotransmitter-like Secretion? Trends in Cell Biology, 13(2003):282-285.

Baluska, F; Volkmann, D and Menzel, D. Plant Synapses: Actin-based domains for Cell-to-Cell Communication, Trends in plant science, 10 (2005):106-111.

Baluska, F; Mancuso, S; Volkmann, D and Barlow P W. The 'root-brain' Hypothesis of Charles and Francis Darwin: Revival after more than 125 years, Plant signaling \& behavior, 4 (2009):11211-127.

Banerjee, B. The Scientist and the Poet: Acharya Jagadish Chandra Bose and Rabindranath Tagore, Rupkatha J. Interdiscip. Study in Humanities, 2 (2010):471-479.

Barlow, P W. Reflections on 'Plant Neurobiology', Bio Systems, 92(2008):132-147.

Bose, J C. On Polarisation of Electric Rays by Double Refracting Crystals, The Electrician, 36 (1895):289290.

Bose, J C. On Double Refraction of the Electric Ray by a Strained Dielectric, The Electrician, 36 (1895): 290291.

Bose, J C. On a New Electropoloriscope, The Electrician, 36(1895):291-92.

Bose, J C. On the Determination by Diffraction Grating, Proc $R$ Soc, A (1896):167-178.

Bose, J C. On a Self-recovering Coherer and the Study of the Cohering Actions of Different Metals, Proc R Soc. A 65 (1899):166-172.

Bose, J C. On the Similarily of Effect of Electrical Stimulus on Inorganic and Living Substrances, The Electrician, 1900.

Bose, J C. On the Strain Theory of Photographic Action, Proc R Soc, A (1901):185-193.

Bose, J C. On the Electric Response in Ordinary Plants under Mechanical Stimulus, J Linn Soc, 35(1902):275-304.

Bose, J C. Plant Response as a means of Physiological Investigation, Longmans, Green, \& Co., London, 1906.

Bose, J C. Response in the Living and non-living [online]. Available at: http://books.google.com/ books?id=GHdGAQAAMAAJ.

Bose, J C. Comparative Electro-physiology, Longmans, Green, and co., London, 1907. 
Bose, J C. Automatism in Plant and Animal, Published in Modern Review, 1908 (Reproduced in J C Bose Speaks), 252-259.

Bose, J C. Mechanical and Electrical Response in Plants: Read before the British Association, Dublin, 1908.

Bose, J C. Automatism in Plant and Animal, Modern Review, (1908):252-265.

Bose, J C. Action of Drugs in Plants (Lecture at the Royal Society of Medicine, London), Proc R Soc Med, 8 (1914):1-40.

Bose J C. Control of Nervous Impulse: Talk: First Anniversary Meeting the Bose Institute 1918, 265267.

Bose, J C. On conduction of Excitation in Plants, Trans. Bose. Res Inst, 1 (1918):97-106.

Bose, J C. The Surge of Life: Published Talk: Delivered at the Bose Institute, 1921, pp. 272-279.

Bose, J C. Circulation and Assimilation in Plants, Proc $R$ Soc Med, 17(1924):19-24

Bose, J C. The Physiology of Photosynthesis, Longmans, London, 1924.

Bose, J C. How Plants move their Limbs? Manchester Guardian, 1925, 309-313.

Bose, J C. The Nervous Mechanism of Plants, Longmans, London, 1926.

Bose, J C. Plant Autographs and their Revelations, Longmans, Green, London, 1927.

Bose, J C. Address at the Tenth Anniversary of the Bose Institute (Reproduced in J C Bose Speaks), 1927, pp.188-195.

Bose, J C. The Motor Mechanism of Plants, Longmans, London, 1928.

Bose, D M. Jagadish Chandra Bose (1858-1937), Biographical Memoirs Fellows National Institute of Sciences of India, Indian National Science Academy publication, vol.1, 1966.

Brenner, E D; Stahlberg, R; Mancuso, S; Vivanco, J; Baluska, F and Van Volkenburgh E. Plant Neurobiology: an Integrated view of Plant signalling, Trends in plant science, 11(2006):413-419.

Burdon-Sanderson, John S I. Note on the Electrical Phenomena which accompany Irritation of the Leaf of Dionæa muscipula, Proceedings of the Royal Society of London, 21(1873):495-496.
Cajal, Santiago Ramon Y. Quoted by Newman E.A. et al: In: The Beautiful Brain. The Drawings of Santiago Ramon Y Cajal, Abram, New York, 2017.

Chaudhuri, A. CA. Jagadish Chandra Bose: The First Indian Biophysicist, Asian Agri-History, 13 (2009):315-319.

Darwin, C. Insectivorous Plants, John Murray, London, 1875.

Darwin, C. The Power of Movements in Plants, John Murray, London, (Quoted by Barlow 2008), 1880.

Dasgupta, S. Jagadis Bose, Augustus Waller and the Discovery of 'Vegetable Electricity', Notes and Records of the Royal Society of London, 52(1998):307-322.

Davies E. Intercellular and Intracellular Signals and their Transduction via the Plasma Membrane-cytoskeleton Interface, Seminars in Cell Biology, 4(1993):139-147.

Eccles, J C. The Neurophysiological basis of Mind: The Principles of Neurophysiology, 1953.

Eccles. The Physiology of Synapses, Academic Press, New York, 1964.

Galston, A W and Slayman, C L. The Not-So-Secret Life of Plants: In which the Historical and Experimental myths about Emotional communication between Animal and Vegetable are put to rest, American Scientist, 67(1979):337-344.

Hubel, D H and Wiesel T N. Receptive Fields of single Neurones in the cat's Striate Cortex. The Journal of physiology, 148(1959):574-591.

Mountcastle, V B. Modality and Topographic Properties of single Neurons of cat's Somatic Sensory Cortex, Journal of Neurophysiology, 20 (1957):408-434.

Muday, G K. Brown-Harding H. Nervous system-like signaling in plant defense, Science, 361(2018):10681069.

Nandy, A. Alternative Sciences: Creativity and Authenticity in Two Indian Scientists, Oxford University Press, 2001 .

Shepherd, V A. From Semi-conductors to the Rhythms of Sensitive Plants: The Research of J C Bose, Cellular and Molecular Biology, 51 (2005):607-619.

Stahlberg, R. Historical overview on Plant Neurobiology, Plant Signaling \& Behavior, 1(2006):6-8.

The Times, 1920: Quoted by J.C. Bose: Address delivered at the $10^{\text {th }}$ Anniversary of the Bose Institute 29 
November, 1927 (Reproduced in J.C. Bose Speaks, p. 193).

Toyota, M; Spencer, D and Sawai-Toyota S, et al. Glutamate Triggers Long-distance, Calcium-based Plant Defense Signaling., Science, 361(2018):1112-1115.

Trewavas, A. How Plants Learn, Proceedings of the National Academy of Sciences of the United States of America, 96 (1999):4216-4218.
Trewavas, A. Green Plants as Intelligent Organisms. Trends in Plant Science, 10(2005):413-419.

Volkov, A G. Plant Electrophysiology: Theory and Methods, Springer, Berlin, 2010.

Zawadzki, T; Davies, E; Dziubinska, H and Trebacz, K. Characteristics of Action Potentials in Helianthus Annuus, Physiologia Plantarum, 83(1991):601604. 